\title{
Vegetative Growth and Yield Associated Flowering Time Variation in Sri Lankan Rice "Hondarawala"
}

\author{
E. U. U. Rathnathunga ${ }^{1}$, S. G. J. N. Senanayake ${ }^{2}$, N. Dissanayake ${ }^{3}$, \\ S. Seneweera ${ }^{4}$ and S. Geekiyanage ${ }^{2 *}$
}

Received: 09 $9^{\text {th }}$ June 2015 / Accepted : $21^{\text {st }}$ Septeber 2015

\begin{abstract}
Breeding new varieties adaptable for changing climate is an essential need in sustainable rice production. Around 2000 Sri Lankan rice accessions at Plant Genetic Resources Centre (PGRC), Sri Lanka have not been fully characterized for the yield potential and sensitivity to mild photoperiodic differences for days to flowering (DF). DF is a candidate key determinant in yield components in rice and understanding the physiological and molecular nature for DF is important to manipulate crop yield through breeding programmes. The objective of this study was to assess the genetic diversity of 15 Hondarawala accessions from PGRC using selected 37 morphological characters and DF. DF varied from 58-189 days while accession number 3988 did not flower until 200 th day of seed germination. Principal Component Analysis (PCA) revealed that four principle components (PA) explained $86.5 \%$ of total observed variation. Variation of $D F$ positively associated with most of morphological characters of vegetative growth while a few characters were negatively associated. In the dendogram, 10 clusters formed at rescale distance of 5. Widely variable DF accessions distributed among clusters.
\end{abstract}

Keywords: Days to flowering, genetic diversity, morphological characters, Sri Lankan rice

\section{INTRODUCTION}

Rice is the most important food crop in Sri Lanka contributing to more than $40 \%$ of daily calorie requirement. There is a wide variation in DF among Asian origin rice which is distributed in a range of agro-ecological zones in the region (Lu and Chang 1980). DF had affected the ecological adaptation of rice (Izawa, 2007). Sri Lankan traditional rice germplasm which is conserved at PGRC, Sri Lanka, consists of around 2000 accessions. Sri Lankan traditional rice germplasm is relatively a large genetic resource in a geographically small island of Sri Lanka. There is a genetic diversity among accessions as they exhibit a wide variation in morphology and DF. Reasonable information on genetic and molecular mechanism of DF in rice is available (Yano and Izawa, 2005).

However, Sri Lankan rice germplasm has rarely been used in flowering time studies except for the work by Chandrarathna (1964) mainly.

Increased and stable rice production is required for increasing population during the era of climate change. New adaptation strategies are needed to develop new varieties to meet these challenges. The genetic potential of Sri Lankan traditional rice has not been completely characterized and exploited for its potential contribution in breeding for yield increment. $\mathrm{DF}$ in rice is controlled by both genetic factors and environmental signals. Photoperiod and temperature are the two main environmental signals that determine the flowering time in rice (Songet al, 2012).

${ }_{4}$ Centre for Systems Biology, University of Southern Queensland, Toowoomba, QLD 4350, Australia. 
Molecular basis for DF had been explained through many quantitative trait loci (QTLs): Hdl (Yano et al, 2000), Hd3a (Kojima et al, 2002), Ehdl (Doiet al, 2004), Ghd7 (Xueet al, 2008), RFT1 (Komiya et al, 2002). Matsuzakiet $a l$, (2015) have demonstrated that the circadian clock is a regulatory network of multiple genes that retains accurate physical time of day by integrating the perturbations on individual genes under fluctuating environments in the field.

It is evident that different temperatures (of low country and hill country) in different ecological regions in Sri Lanka affect DF of rice. Effect of temperature at different phases of rice growth has not been completely studied. Among the known flowering time genes of rice, Ehdl and Hd1 together control panicle development (Endo-Higashi and Izawa, 2011). DTH8, a QTL for DF is located on chromosome 8, also regulate yield potential and plant height (Wei et al, 2010). However, it is not known how these interact with each other on the crop yield potential. When three Sri Lankan traditional rice genotypes were grown under long day (LD), day neutral $(\mathrm{DN})$ and short day (SD) photoperiods, days to flowering were increased under $\mathrm{LD}$ while there was an inverse relationship between enhanced vegetative growth and yield (Geekiyanage, 2012). The above traditional rice genotypes may represent the general response of Sri Lankan traditional rice germplasm on relationship between DF and, vegetative growth and yield. To test the relationship between DF and, vegetative growth and yield components of a Sri Lankan traditional rice in which several accessions are listed for one variety at PGRC, we selected Hondarawala variety which consisted of 15 accessions. As Hondarawala had been identified as suitable for low phosphorus field conditions, it had been exploited in breeding programmes for new improved varieties at IRRI.

In Sri Lanka, the cultivation of traditional rice varieties had largely eliminated from regular farmer field due to introduction of new improved varieties claiming desired plant type and yield. Currently, the maximum yield potential has been achieved in improved rice while there are needs for improvement of the rice quality. Therefore genetic resources of traditional rice must be utilized for further yield increase strategies for both yield and quality enhancement. We used the accessions of same variety Hondarawala with different DF for the experiment. The objectives of the experiment were to analyze the variation of DF, vegetative growth and yield among accessions and relationships between DF and vegetative growth and yield.

\section{MATERIALS AND METHODS}

\section{Rice Accessions}

Fifteen accessions of Sri Lankan traditional rice variety Hondarawala (Accession numbers: 3906, 6198, 4070, 4071, 3988, 3678, 3850, $3977,6199,6690,6428,4243,3521,3528$, 6200) were obtained from Plant Genetic Resources Center (PGRC), Sri Lanka.

\section{Field Experiment}

Rice accessions were grown at Rice Research and Development Institute, Batalagoda, Sri Lanka (in IL1 agro ecological zone, latitude $7^{\circ}$ $29^{\prime} 12^{\prime \prime} \mathrm{N}$ and longitude $80^{\circ} 21^{\prime} 53^{\prime \prime} \mathrm{E}$ with a height above MSL 137m). Average ambient temperature during the cropping season was $30{ }^{\circ} \mathrm{C}$ and the soil was Dark brown earth (DBE). Each replicate consisted of $3 \mathrm{~m}$ long 3 row-plots with 9 plants: $20 \mathrm{~cm} \times 20 \mathrm{~cm}$ within and between rows and $40 \mathrm{~cm}$ between plots in a Completely Randomized Design (CRD) with 4 replicates. The experiment was carried out in wet season during north eastern monsoon (Maha), 2012/2013 during which day length varies 11-11.5 hours in Sri Lanka. The seeds were sown in the upland nursery bed in December, 2012 with $15 \mathrm{~cm}$ spacing in between each accession. Seedlings were transplanted by 21-days. Fertilizer application, pest and disease 
management and weed control were according to the recommendation by Department of Agriculture, Sri Lanka. The basal dressing of urea, TSP and MOP (as in the ratio of N: P: $\mathrm{K})$ was applied during land preparation. Top dressing of 25,50 and $50 \mathrm{~kg} / \mathrm{ac}$ of urea were applied at 2 weeks, 5 weeks and 7 weeks of planting respectively. Manual weeding was done at regular intervals and the competition from weeds was kept minimal. Approximately permanent standing water level of $5 \mathrm{~cm}$ was maintained throughout the experiment.

\section{Evaluation of morphological traits}

Thirty seven morphological characters; 15 quantitative and 21 qualitative characters and DF were recorded (Table: 01 ). With respective to each character in a given accession, average value of replicates was considered for analysis. Data were collected at heading and at harvest of each variety. Measurement techniques were based on descriptors of rice published by the Team of NRC research project 12-129 (2014), International Rice Research Institute (1980 and 2007) and PGRC (2006).

\section{Statistical analysis}

Data were analyzed using PCA with correlation matrix through SPSS software (version 20), IBM, USA to define the patterns of variation between all explanatory variables. Grouping of variables into PCs was noted and thereby the dimension of the data set reduced. The 14 accessions which flowered during the experimental period of 200 days were clustered using Hierarchical Cluster analysis through SPSS software (version 20); IBM, USA which grouped and sorted the closely related accessions into clusters, using the first four PC scores of varieties. Measure of dissimilarity was the Euclidean distance and the clustering method was Ward's linkage. The number of clusters was determined at the rescaled distance of 5 .

\section{RESULTS AND DISCUSSION}

\section{Variation in DF among Hondarawala accessions}

DF and quantitative morphological charactersof vegetative growth and yield components were largely varied among all Hondarawala accessions (Table: 02 and 03). DF among 15 accessions varied from 58-189 day while accession number 3988 did not flower until $200^{\text {th }}$ day of seed germination. Seeds had been germinated in late January, 2013 which was the end of mild short day season in Sri Lanka under natural field conditions during which the photoperiod changes from short day to long day. As a result, the inductive photoperiod durations may have changed over time. Vegetative growth phase, reproductive phase and ripening phase are the 3 main phases of rice growth (Vergara and Chang, 1985). In vegetative growth phase, there are 2 sub-phases as basic vegetative phase (BVP) which is the photoperiod insensitive vegetative phase and photoperiod sensitive phase (PSP). BVP is a highly variable time duration which may be genetically controlled (Chandrarathna, 1964). In Hondarawala accessions DF varied from 58 to $200+$ days indicating that juvenile period of BVP is variable among them. Additionally, effect of temperature variation during the period may have played a role in determining the DF.

Duration from panicle initiation (PI) to flowering is also affected by photoperiod (Coolhaas and Wormer, 1953; Best, 1961; Janardhan and Murty, 1967). Based on results in a rice cultivar, Collinson et al., (1992) found that PI occurred when about $80 \%$ of the PSP had elapsed in a rice cultivar. These findings suggest that wide variation of DF among accessions and nonflowering at non-inductive photoperiod must be highly determined by the genetic factors of each accession. 
Table 01: The quantitative and qualitative characters measured during the experiment

\begin{tabular}{lc}
\hline \multicolumn{1}{c}{ Character } & Abbreviation \\
\hline Plant height at maturity & PH \\
Culm length at maturity & CL \\
Culm number at maturity & CN \\
Culm diameter at maturity & CD \\
Panicle length at maturity & PL \\
Grain length at maturity & GL \\
Grain width at maturity & GW \\
Leaf number at maturity & LN \\
Leaf length at maturity & LL \\
Leaf width at maturity & LW \\
Ligule length at maturity & LiL \\
Root length at maturity & RL \\
Shoot weight at maturity & SW \\
Panicle weight at maturity & PW \\
Plant height at vegetative stage & PHV \\
Culm number at vegetative stage & CNV \\
Leaf angle & LA \\
Flag leaf angle & FLA \\
Leaf blade puberscence & LBP \\
Leaf blade Colour & LBC \\
Leaf senescence & LS \\
Ligule colour & LiC \\
Ligule shape & LiS \\
Internode color & IC \\
Culm angle & CA \\
Culm strength & CS \\
Panicle type & PT \\
Panicle exertion & PE \\
Panicle axis & PA \\
Secondary branching & SB \\
Awning after full heading & AP \\
Awn colour & AC \\
Apiculus colour & ApC \\
Lemma and palea colour & LPC \\
Lemma and palea puberscence & LPP \\
Pericarp colour & PCC \\
Sterile lemma colour & SLC \\
\hline
\end{tabular}


Table 02: Descriptive statistical explanation of the variation of quantitative characters among the accessions of Sri Lankan traditional rice variety Hondarawala.

\begin{tabular}{ccccc}
\hline Character & Unit & Range & Average & Standard Deviation \\
\hline DF & Days & $58-200+$ & 111.50 & 39.32 \\
PH & $\mathrm{cm}$ & $119.68-198.25$ & 163.14 & 20.16 \\
CL & $\mathrm{cm}$ & $99.10-155.00$ & 119.83 & 14.16 \\
$\mathrm{CN}$ & Number & $10-42$ & 18.48 & 8.57 \\
$\mathrm{CD}$ & $\mathrm{mm}$ & $4.5-6.5$ & 5.80 & 0.99 \\
PL & $\mathrm{cm}$ & $5.70-28.50$ & 23.19 & 5.82 \\
GL & $\mathrm{mm}$ & $6.8-14.8$ & 7.50 & 0.64 \\
GW & $\mathrm{mm}$ & $2.5-4.0$ & 3.10 & 0.44 \\
LN & Number & $30-148$ & 69.52 & 20.79 \\
LL & $\mathrm{cm}$ & $42.46-75.90$ & 62.17 & 9.41 \\
LW & $\mathrm{mm}$ & $9.4-14.4$ & 11.77 & 1.30 \\
LiL & $\mathrm{cm}$ & $0.70-2.68$ & 1.77 & 0.59 \\
RL & $\mathrm{cm}$ & $11.5-30.0$ & 20.09 & 5.42 \\
SW & $\mathrm{g}$ & $93.33-415.93$ & 166.62 & 65.50 \\
PW & $\mathrm{G}$ & $2.48-44.90$ & 14.17 & 11.75 \\
PHV & $\mathrm{Cm}$ & $121.00-157.20$ & 142.89 & 11.75 \\
CNV & $\mathrm{Number}$ & $11-23$ & 16.81 & 2.94 \\
\hline
\end{tabular}

Table 03: Variation of quantitative characters of Sri Lankan traditional rice variety Hondarawala within clusters derived through Ward's linkage method.

\begin{tabular}{cccccccccc}
\hline \multirow{2}{*}{$\begin{array}{c}\text { Cluster } \\
\text { Number }\end{array}$} & $\begin{array}{c}\text { PGRC } \\
\text { accession } \\
\text { number }\end{array}$ & DF & $\begin{array}{c}\text { PH } \\
(\mathrm{cm})\end{array}$ & CN & LN & $\begin{array}{c}\text { LL } \\
(\mathrm{cm})\end{array}$ & $\begin{array}{c}\text { LiL } \\
(\mathrm{cm})\end{array}$ & $\begin{array}{c}\text { LW } \\
(\mathrm{mm})\end{array}$ & $\begin{array}{c}\text { PW } \\
(\mathrm{g})\end{array}$ \\
\hline \multirow{2}{*}{1} & 3977 & 68 & 129.3 & 14 & 71 & 50.4 & 0.7 & 12.2 & 15.1 \\
& 6199 & 96 & 156.3 & 13 & 55 & 64.7 & 2.1 & 13.4 & 10.0 \\
2 & 6428 & 58 & 119.7 & 17 & 67 & 42.5 & 1.7 & 11.0 & 23.1 \\
3 & 3850 & 131 & 180.5 & 19 & 57 & 66.9 & 2.1 & 11.2 & 6.8 \\
4 & 3521 & 189 & 172.7 & 23 & 91 & 67.6 & 1.6 & 11.2 & 9.9 \\
5 & 6690 & 119 & 175.8 & 29 & 114 & 68.4 & 2.3 & 12.0 & 7.9 \\
6 & 3906 & 79 & 160.0 & 16 & 30 & 66.8 & 1.2 & 12.8 & 18.2 \\
7 & 3528 & 186 & 172.0 & 42 & 39 & 75.9 & 0.7 & 11.2 & 13.2 \\
8 & 4243 & 99 & 149.0 & 24 & 81 & 56.9 & 2.1 & 11.4 & 44.9 \\
& 6200 & 82 & 173.3 & 10 & 59 & 50.5 & 1.8 & 14.4 & 30.3 \\
9 & 6198 & 141 & 198.3 & 16 & 78 & 73.8 & 2.5 & 9.4 & 2.5 \\
& 4070 & 104 & 165.5 & 13 & 63 & 58.5 & 1.9 & 10.0 & 6.8 \\
10 & 4071 & 103 & 165.8 & 13 & 63 & 64.1 & 1.6 & 12.0 & 4.9 \\
$*$ & 3678 & 106 & 166.0 & 13 & 72 & 63.3 & 2.7 & 12.6 & 4.9 \\
\hline
\end{tabular}

*Accession number 3988 of which days to flowering exceeded the experimental period of 200 days was not included in the Cluster Analysis. 
Relationship between days to flowering on variation in qualitative morphological characters

Except for the colour of ligule, all other 20 qualitative morphological characters were varied among accessions (Table: 04). Occurrence of heavy secondary branching in the panicle was observed in the longest DF accessions of 3528 and 3521.

Several workers of Yu et al., (1995), Yoshimura et al. (2001), Rutger and Mackill (2001), Rutger and Tai (2005) had reported that genes for hairs on rice leaf and hull are linked: According to $\mathrm{Hu}$ et al., (2013) all glabrous leafy rice produced glabrous hulls while hairy leafy rice produced hairy hulls. However, all Hondarawala accessions produced pubescent hulls and glabrous or pubescent leaves irrespective of DF variation indicating a genetic diversity of Hondarawala for leaf and hull pubescence. Further, a variety of pericarp colours and lemma and palea colours was observed indicating the allelic richness among accessions.

There were awns in all seeds only in one accession while others were without awns or partly awned. DF did not have a relationship with the presence of awns (Table:04).

\section{Relationship between days to flowering on quantitative morphological characters}

The correlation analysis revealed that there were strong significant positive correlations between DF and morphological characters of PH, CL, LL, RL, SW, PHV, LN and CNV while LW and PW were negatively correlated with DF (Table: 05). DF among accessions was a major determinant in quantitative morphological characters and yield components. Delayed flowering time increased the vegetative growth and reduced the panicle weight. Similarly, in our preliminary studies with Sri Lankan traditional rice varieties of Devaraddili and Kohu Ma wee under SD, LD and DN conditions, Deveraddlili and Kohu Ma wee did not flower by $200^{\text {th }}$ at under LD condition and tiller number was significantly increased. Under DN condition, DF delayed in contrast to SD and yield was reduced (Geekiyanage et al, 2012). Tehrim et al (2012) had reported that DF of different rice genotypes was positively associated with days to maturity and straw yield per plant while DF negatively associated with seed setting percentage and harvest index.

In an experiment on photoperiodic effect fewer than four combinations of genetic compositions of $H d l$ and Ehdl, $H d l$ expression in nonfunctional $h d l$ and ehdl background under LD increased the DF and tiller number with reduced spikelet number (Endo-Higashi and Izawa, 2011). Although genetic factors of the accessions have not been revealed, our observation during this experiment supports the above report as DF negatively correlated with total panicle weight. Although Endo-Higashi and Izawa (2011) reports that Ehdl and $H d l$ together suppress number of panicles and number of spikelets under SD with the shortest DF, in Hondarawala accessions, short DF increased the panicle weight (Table:03) indicating a different genetic control in flowering time.

\section{Principal Component Analysis and Cluster Analysis}

First four PCs explained $86.5 \%$ of total observed variation. (Table: 06). In PCA, most of the morphological characters of vegetative growth ( $\mathrm{PH}, \mathrm{CN}, \mathrm{LN}, \mathrm{LL}, \mathrm{RL}$ and $\mathrm{LL})$ which were affected by DF, included in simultaneous PCs with complex structures. Four PCs were rearranged removing the complex structures. Variation in DF among accessions was clearly exhibited within each cluster.

In the Hierarchical Cluster Analysis, ten clusters were formed at rescale distance of 5 (Figure: 01). DF varied within each cluster (Table: 03). At rescaled distance less than 5 even, there were 3 clusters with more than one accession in each (Figure: 01): Accessions 3977 and 6199 are grouped in one such cluster, except for LW, quantitative characters of DF, PH. LN, LL and 
PW, and qualitative characters of LBP, PT, and PA were different from each other (Table: 03 and 04). Accession numbers 3850 and 3521 in third cluster were different to each other by quantitative characters of DF, PW and LN and qualitative characters of AC, AP, LPC,

Table 04: Variation of qualitative characters within clusters derived through Ward's linkage method.

Interm: - Intermediate

a. Brownish black/ b. Brown furrows on gold background/ c. Brown seed coat with white strip

*Accession number 3988 of which days to flowering exceeded the experimental period of 200 days was not included in the Cluster Analysi

Table 05: Correlation among the quantitative characters within accessions of Sri Lankan traditional rice variety Hondarawala.

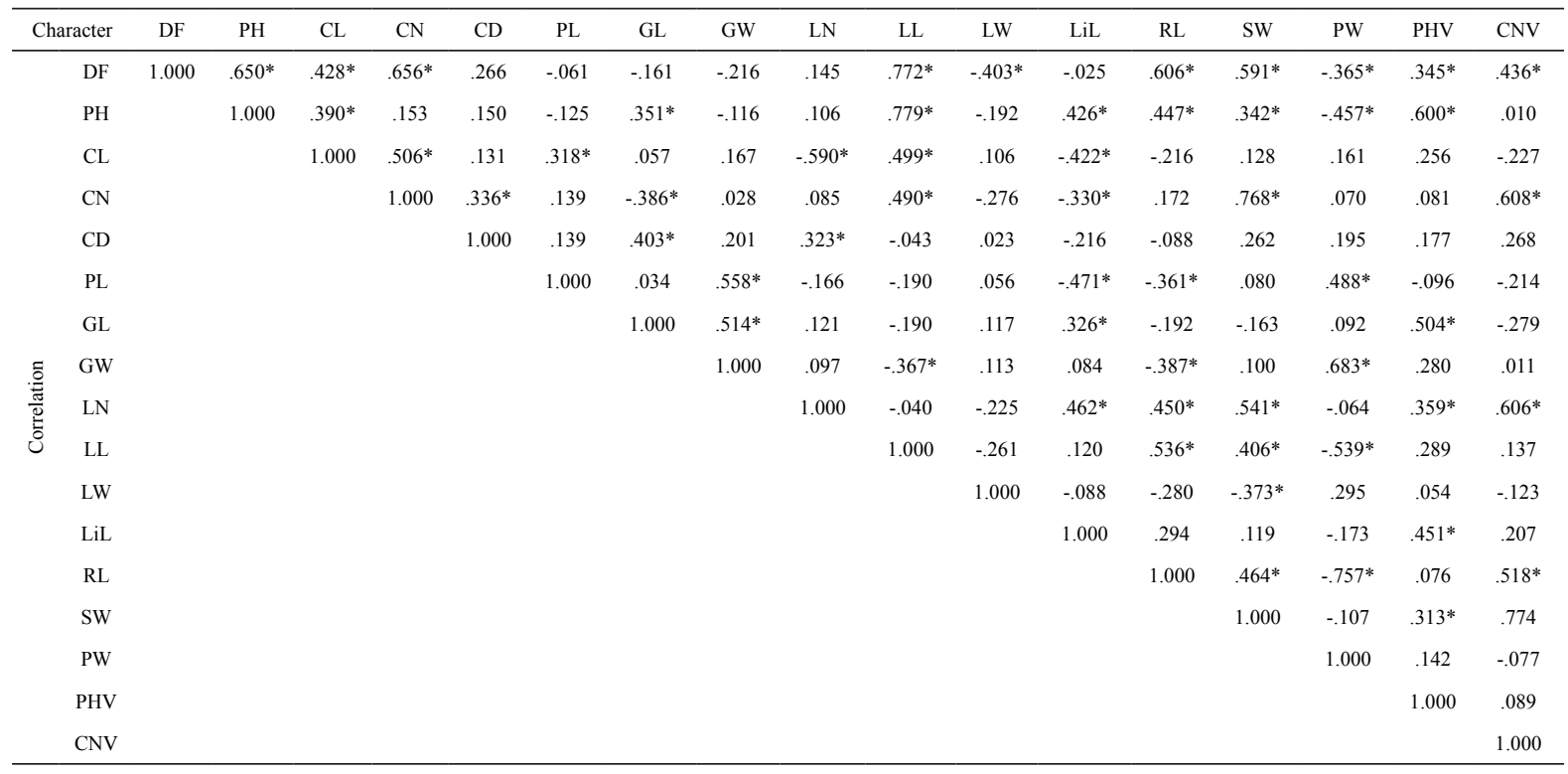

$*>0.3$, significant correlation $(+)$ positive, $(-)$ negative 
Table 06: First four PCs on variation among accessions of Sri Lankan traditional rice variety Hondarawala

\begin{tabular}{ccccc}
\hline PC & PC 1 & PC 2 & PC 3 & PC 4 \\
\hline $\begin{array}{c}\text { Contribution } \\
\text { to variation }\end{array}$ & $31.7 \%$ & $23.8 \%$ & $17.8 \%$ & $13.2 \%$ \\
$\begin{array}{c}\text { Composition } \\
\text { of characters }\end{array}$ & $\mathrm{PW}(0.787)$ & $\mathrm{CNV}(0.930)$ & $\mathrm{PHV}(0.837)$ & $\mathrm{CL}(0.945)$ \\
& $\mathrm{PL}(0.857)$ & $\mathrm{SW}(0.942)$ & $\mathrm{GL}(0.869)$ & \\
\hline
\end{tabular}

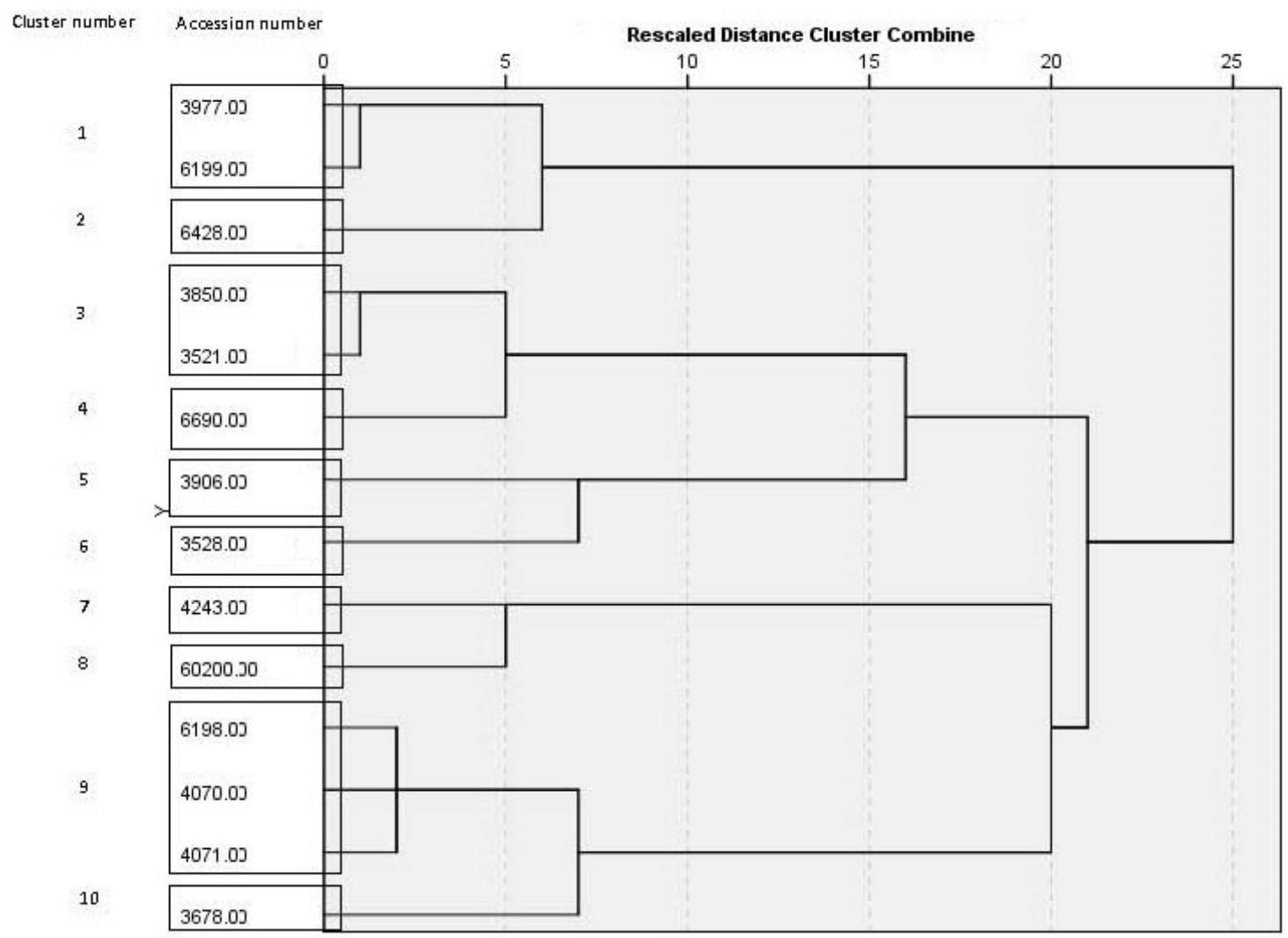

Figure 01: Dendogram of Hondarawala accessions derived through Ward's linkage method of Cluster Analysis based on 17 vegetative and yield characters.

Based on the cluster analysis, accessions with distinct flowering times and related morphological characters can be identified. Genes responsible for DF may associate with genes for morphological characters or DF genes are pleiotropic. In our attempt to identify the relationship between DF in Sri Lankan rice accessions of Hondarawala and morphological characters of vegetative and yield could be useful in future breeding programmes for yield increment.

\section{CONCLUSION}

DF and quantitative morphological characters of PH, CL, CN, CD, PL, GL, GW, LN, LL, LW, LiL, RL, SW, PW, PHV and CNV varied among 15 accessions.

Qualitative morphological characters of LA, FLA, LBP, LBC, LS, LiS, IC, CA, CS, PT, PE, PA, SB, AP, AC, ApC, LPC, LPP, PCC and SLC were varied among accessions. Vegetative 
morphological characters of $\mathrm{PH}, \mathrm{CL}, \mathrm{LL}$, RL, SW, PHV, LN and CNV were positively correlated with DF while LW and PW (a yield component) were negatively correlated. First four Principal components (PA) explained $86.5 \%$ of total observed variation among accessions.

\section{REFERENCES}

Best K. (1961). Some aspects of photoperiodism in rice ( Oryza sativa L.). Elsevier, Amsterdam. 87.

Chandraratna M. F. (1964). Rice plant physiology and photoperiod of rice. Genetics and breeding of rice. Longmans, London. 389.

Collinson S.T. Summerfield R.J. Ellis R.H. Roberts E.H. (1992). Durations of the photoperiod sensitive and the photoperiod insensitive phases of development to flowering in four cultivars of rice (Oryza sativa L.) Annals of Batany 70: 339-346.

Coolhaas C. and Wormer T.M. (1953). Developmental difference in rice plants in relation to photoperiodism. Neth. J. Agric. Sci. 1:202-216.

Doi K. Izawa T. Fuse T. Yamanouchi U. Kubo T. Shimatani Z. Yano M. and Yoshimura A. (2004). Ehd1, a B-type response regulator in rice, confers short-day promotion of flowering and controls FT-like gene expression independently of Hd1. Genes Dev. 18: 926-936.

Endo-Higashi N. and Izawa T. (2011). Flowering Time Genes Heading date 1 and Early heading date 1, Together Control Panicle Development in Rice, Plant Cell Physiol. 52(6): 10831094.

Geekiyanage S. Madurangi S.A.P. and Rathnathunga E.U.U. (2012). Effect of photoperiod on flowering time and attributed traits of selected Sri Lankan rice varieties, 10th Academic sessions, University of Ruhuna. 70.

Hu D. Smith E.R. Garruss A.S. Mohaghegh N. Varberg J.M. Lin C. Jackson J. Gao X. Saraf A. Florens L. Washburn M.P. Eissenberg J.C. Shilatifard A. (2013). The Little Elongation Complex Functions at Initiation and Elongation Phases of snRNA Gene Transcription. Mol. Cell 51(4): 493--505.

International Board for Plant Genetic Resources-International Rice Research Institute and Rice Advisory Committee. (1980). Descriptors For Rice Oryza sativa l., International Rice Research Institute, Los Baños, Laguna, Philippines.

International Rice Research Institute and Biotechnology International. (2007). Descriptors for wild and cultivated Rice (Oryza spp.) International Network for the Improvement of Banana and Plantain and International Plant Genetic Resources, International Rice Research Institute, Los Baños, Laguna, Philippines. 
Izawa T. (2007) Adaptation of flowering time by natural and artificial selection in Arabidopsis and rice. J Exp Bot. 58:3091-3097.

Janardhan K.V. and Murty. K.S. (1967). Effect of photoperiod on panicle emergence in rice. Curr. Sci. 36:382-383.

Kojima Y. Ebana K. Fukuoka S. Nagamine T. and Kawase M. (2005). Development of an RFLPbased rice diversity research set of germplasm. Breeding Science. 55:431:440.

Komiya R. Yokoi S. and Shimamoto K. (2008). Hd3a and RFT1 are essential for flowering in rice. Development. 136:3443-3450.

Lu J.J. and Chang T.T. (1980). Rice in its temporal and special perspectives. In: LuhBs (ed) Rice: production and utilization. AVI publishing Coinc, Westport. 1-74.

Matsuzaki, J., Kawahara, Y., and Izawa, T. (2015). Punctual Transcriptional Regulation by the Rice Circadian Clock under Fluctuating Field Conditions. The Plant Cell, 27(3): 633-648.

Plant Genetic Resource Center, (2006). Characterization Catalogue on Rice (Oryza sativa) Germplasm, Department of Agriculture. Sri Lanka.

Rathnathunga E.U.U. Pushpakumari W.H.D.U. Padukkage P.D.C. Dissanayake, N. Fernando K. Rathnasiri, P.W. Senanayake, G. Senaweera, S. and Geekiyanage, S. (Team of NRC research project 12-129), (2014). Handbook on Varietal Diversity of Sri Lankan Traditional Rice (Oryza sativa L.), University of Ruhuna, Sri Lanka, ISBN: 978-955-0263-01-1.1: 82.

Rice Research and Development Institute, Sri Lanka, website DOASL, Rice Knowledge Bank, International Rice Research Institute, Retrieved on June 14, 2014, (http://www. knowledgebank,irri.org/SriLanka/padd-vari.html/) .

Roberts E.H. Summerfield R.J. (1987). Measurement and prediction of flowering in annual crops. In: Atherton JG, ed. Manipulation of flowering. London: Butterworths, 17-50.

Rutger J.N. and Mackill. D.J. (2001). Application of mendelian genetics in rice breeding. In: G.S. Khush, D.S. Brar, and B. Hardy, editors, Rice genetics IV. International Rice Research Institute, Los Baños, Philippines; Science Publishers, Inc., Enfield, NH.27-38.

Rutger J.N. and Tai. T.H. (2005). Registration of K/Z mapping population of rice. Crop Sci. 45:2671-2672. doi:10.2135/cropsci2005.0172

Song Y.L. Gao Z.C. and Luan W.J. (2012). Interaction between Temperature and Photoperiod in regulation of flowering time in rice, Science China, 55 (3): 241-249.

Tehrim, S., Pervaiz, Z. H., Mirza, M. Y., Rabbani, M. A., and Masood, M. S. (2012). Assessment of phenotypic variability in rice (Oryza sativa L.) cultivars using multivariate analysis. Pak. J. Bot, 44(3): 999-1006.

Vergara B.S. and Chang T.T. (1985). The Flowering Response of the Rice Plant to Photoperiod, A review of the literature, International Rice Research Institute. Los Baños, Laguna, Philippines. 
Wei X. Xu J. Guo H. Jiang L. Chen S. Yu C. Zhou Z. Hu P. Zhai H. and Wan J. (2010). DTH8 Suppresses Flowering in Rice, Influencing Plant Height and Yield Potential Simultaneously. Plant Physiology.153: 1747-1758.

Xue W. Xing Y. Weng X. Zhao Y. and Tang W. (2008) Natural variation in Ghd7 is an important regulator of heading date and yield potential in rice. Nat Genet. 40:761-767

Yano M. Kojima S. Takahashi Y. Lin H.X. and Sasaki T. (2001) Genetic control of flowering time in rice, a short day plant. Plant Physiol. 127:1425-1429

Yano M. and Izawa T. (2005). Genetic and molecular dissection of flowering time in rice, Rice Genetics V, Proceedings of the Fifth International Rice Genetics Symposium, International Rice Research Institute. Los Baños, Laguna, Philippines. 355.

Yoshimura A. N. Takano-Kai T. Eguchi M. Ashikari O. Ideta K. Doi and H. Yasui. (2001). RFLP mapping of 95 morphological trait loci in rice. Breed Res. 3 (Suppl. 1):94.

Yu, Z.H., S.R. Mc Couch, T. Kinoshita, S. Sato, and S.D. Tanksley. (1995). Association of morphological and RFLP markers in rice (Oryza sativa L.). Genome 38:566-574. doi:10.1139/ g95-073. 